\title{
Validity of Self-reported Hypertension and Factors Related to Discordance Between Self-reported and Objectively Measured Hypertension: Evidence From a Cohort Study in Iran
}

\author{
Farid Najafi', ${ }^{1,2}$, Yahya Pasdar ${ }^{1,3}$, Ebrahim Shakiba ${ }^{4}$, Behrooz Hamzeh $^{1,5}$, Mitra Darbandi' ${ }^{6}$, Mehdi Moradinazar ${ }^{1,2}$, \\ Jafar Navabi ${ }^{4}$, Bita Anvari ${ }^{4}$, Mohammad Reza Saidi ${ }^{2}$, Shahrzad Bazargan-Hejazi ${ }^{7}$ \\ ${ }^{1}$ Research Center for Environmental Determinants of Health, Kermanshah University of Medical Sciences, Kermanshah, Iran; ${ }^{2}$ Kermanshah \\ Cardiovascular Research Center, Kermanshah University of Medical Sciences, Kermanshah, Iran; ${ }^{3}$ Nutritional Sciences Department, School of Public \\ Health, Kermanshah University of Medical Sciences, Kermanshah, Iran; ${ }^{4}$ School of Medicine, Kermanshah University of Medical Sciences, \\ Kermanshah, Iran; ${ }^{5}$ Department of Public Health, Kermanshah University of Medical Sciences, Kermanshah, Iran; ${ }^{6}$ Students Research Committee, \\ Kermanshah University of Medical Sciences, Kermanshah, Iran; ${ }^{7}$ Department of Psychiatry, Charles Drew University of Medicine and Science (CDU), \\ Los Angeles, CA, USA
}

Objectives: Self-reporting can be used to determine the incidence and prevalence of hypertension (HTN). The present study was conducted to determine the validity of self-reported HTN and to identify factors affecting discordance between self-reported and objectively measured HTN in participants in the Ravansar Non-Communicable Diseases (RaNCD) cohort.

Methods: The RaNCD cohort included permanent residents of Ravansar, Iran aged 35-65 years. Self-reported data were collected before clinical examinations were conducted by well-trained staff members. The gold standard for HTN was anti-hypertensive medication use and blood pressure measurements. The sensitivity, specificity, positive and negative predictive values, and overall accuracy of self-reporting were calculated. Univariate and multivariate logistic regression were used to examine the discordance between self-reported HTN and the gold standard.

Results: Of the 10065 participants in the RaNCD, 4755 (47.4\%) were male. The prevalence of HTN was 16.8\% based on self-reporting and $15.7 \%$ based on medical history and HTN measurements. Of the participants with HTN, 297 (18.8\%) had no knowledge of their disease, and 313 (19.9\%) had not properly controlled their HTN despite receiving treatment. The sensitivity, specificity, and kappa for self-reported HTN were $75.5 \%, 96.4 \%$, and $73.4 \%$, respectively. False positives became more likely with age, body mass index (BMI), low socioeconomic status, and female sex, whereas false negatives became more likely with age, BMI, high socioeconomic status, smoking, and urban residency.

Conclusions: The sensitivity and specificity of self-reported HTN were acceptable, suggesting that this method can be used for public health initiatives in the absence of countrywide HTN control and detection programs.

Key words: Hypertension, Self report, Prevalence, Accuracy, Iran

Received: November 7, 2018 Accepted: February 14, 2019

Corresponding author: Mehdi Moradinazar, PhD

Research Center for Environmental Determinants of Health, Kermanshah University of Medical Sciences, Kermanshah 6719851351, Iran

E-mail:m.moradinazar@kums.ac.ir

This is an Open Access article distributed under the terms of the Creative Commons Attribution Non-Commercial License (http://creativecommons.org/licenses/bync/4.0/) which permits unrestricted non-commercial use, distribution, and reproduction in any medium, provided the original work is properly cited.

\section{INTRODUCTION}

The high prevalence of hypertension (HTN) makes it an important contributor to mortality and morbidity worldwide. In fact, high blood pressure (BP) is responsible for $13.0 \%$ of deaths globally, making it one of the leading global risk factors for mortality [1]. During the last 40 years, elevated BP has become more common worldwide, mainly due to population 
growth and aging in low-income and middle-income countries [1], whereas the prevalence of elevated BP in high-income countries has decreased [2]. Globally, approximately two-thirds of stroke cases and one-half of ischemic heart disease cases are attributable to non-optimal BP. These proportions are higher in more developed parts of the world [3].

HTN affects about one billion people worldwide, and it is estimated that by 2025 , up to 1.56 billion adults worldwide will have HTN [4,5]. Worldwide, 7.1 million deaths (approximately $12.8 \%$ of the global total) and 64.3 million disability-adjusted life years ( $4.4 \%$ of the global total) are estimated to be due to non-optimal BP [3].

Since asymptomatic HTN is the most frequent form of HTN, regular BP measurements are the only way to diagnose HTN before the appearance of complications. In fact, HTN and its complications can be effectively controlled by early diagnosis and treatment of this condition. However, the rate of HTN control is very low worldwide [6,7].

Based on the existing evidence, the reduction of mortality due to stroke and heart failure depends largely on the early diagnosis and treatment of HTN, as long as the methods used to identify and treat patients are valid and evidence-based [8]. Thus, public knowledge about the disease, investigations into the prevalence of HTN and the proportion of individuals with HTN who receive treatment in specific regions, and efforts to identify the contributions of associated risk factors are all essential for the successful implementation of prevention strategies [9]. Self-reporting is a way to determine the incidence and prevalence of chronic diseases such as HTN. No previous report has assessed the validity of self-reported HTN in Iran. The present study aimed to determine the validity of self-reported HTN and to identify factors affecting discordance between self-reported HTN and objective measures of HTN among participants in the Ravansar Non-Communicable Chronic Disease (RaNCD) cohort.

\section{METHODS}

\section{Study Design and Subjects}

The RaNCD cohort study is part of the Prospective Epidemiological Research Studies in IrAN (PERSIAN) cohort, focused on permanent residents of Ravansar aged 35-65 years. In the PERSIAN cohort, all 18 cohort sites (covering different samples representative of the entire Iranian people, including different ethnicities) used the same questionnaire, which contained the following sections: general information (demographic information, socioeconomic status, lifestyle factors, occupational history, mobile device use, and physical activity), medical information (past medical history, past and present medicine use, family medical history, obstetric and gynecological history, oral health, and personal habits), and a nutrition questionnaire (food frequency questionnaire, dietary habits, water consumption, and supplement intake). In addition, biological samples containing blood, urine, hair, and nails were collected from all participants. The details of the study design and rationale for conducting the PERSIAN cohort have been presented elsewhere [10-12].

The population of Ravansar County is about 50 000, mainly of Iranian Kurdish ethnicity. In Ravansar County, there are 3 urban and 2 rural healthcare centers, as well as 32 active local primary health care units (health houses) in rural areas. One of the reasons for selecting Ravansar County as the location for this cohort study was that the population is mainly Kurdish, an ethnicity comprising roughly 45 million people in 4 countries who are very similar in culture, nutrition, lifestyle, and even genetic background. Furthermore, Ravansar County is located within $45 \mathrm{~km}$ of Kermanshah University of Medical Sciences, where the investigators of this study are based, which made the research very feasible.

\section{Recruitment, Data Collection, and Measurements}

Participants were invited to the study site for data collection. The PERSIAN cohort questionnaire consisted of 482 items divided into 3 major sections: general, medical, and nutrition. Each section was administered by a trained interviewer. To ensure that all procedures were performed in accordance with the PERSIAN cohort protocol, quality assurance (QA) and quality control $(\mathrm{QC})$ measures were implemented by central and local QA/QC teams [10,11].

Each section was administered by a trained interviewer. There was no assigned order in which the sections needed to be completed; therefore, participants were directed to complete the sections based on the availability of the interviewers. Participants were invited by trained personnel who had a good command of Kurdish and other local languages. The invitation procedure included a face-to-face meeting at the participant's home approximately 1 week prior to the appointment, and the cohort assistant called to remind the participant a day before the appointment.

For the purpose of this study, HTN was defined based on a 
systolic BP level of $\geq 140 \mathrm{mmHg}$ and/or a diastolic BP of $\geq 90$ $\mathrm{mmHg}$, corresponding to the second stage of HTN [13], and/or a history of receiving treatment for HTN, determined by checking participants' current medications. In order to investigate the use of anti-hypertensive treatments, participants were asked to bring all their medications (prescription and overthe-counter medicines) to the study center. Treatment of HTN was defined as current use of a pharmacological medication for the management of high BP. Participants taking an antihypertensive medication who did not show HTN on the day of the questionnaire were classified as having controlled HTN.

We used the wealth index as a proxy for economic status [14]. The wealth index was generated by applying principal component analysis to data on durable goods, housing characteristics, and other amenities. For the purposes of this study, participants were classified by age into 3 groups: $35-45$ years, $46-55$ years, and $56-65$ years.

\section{Statistical Analysis and Calculations}

The validity of self-reported HTN was assessed in terms of sensitivity and specificity. Sensitivity was calculated as (true positives)/(true positives plus false negatives), and specificity as (true negatives)/(true negatives plus false positives). The positive likelihood ratio was defined as sensitivity/(1-specificity), and the negative likelihood ratio as (1-sensitivity)/specificity. The positive predictive value was defined as (true positives)/(true positives plus false positives), and the negative predictive value as (true negatives)/(true negatives plus false negatives).

Univariate and multivariate logistic regression were used to examine the role of demographic, socioeconomic and healthrelated behavioral factors in discordance (false positives and/ or false negatives) between self-reported HTN and the gold standard. All variables with a $p$-value less than 0.3 in the univariate model were included in the multivariate analysis. A 2-sided alpha level of 0.05 was considered to indicate statistical significance. All analyses were carried out using Stata version 14.1 (StataCorp., College Station, TX, USA).

\section{RESULTS}

Of the 10065 participants in the RaNCD cohort, 4755 (47.4\%) were male. The plurality of individuals (44.0\%) were aged 3545 years, and the age category $56-65$ years was the smallest (22.8\%). The mean age of the male participants was $47.8 \pm 8.0$
Table 1. Demographic characteristic of participants of the RaNCD cohort by HTN status

\begin{tabular}{|c|c|c|c|c|}
\hline \multirow[t]{2}{*}{ Variable } & \multirow[t]{2}{*}{ Total } & \multicolumn{2}{|c|}{$\begin{array}{l}\text { HTN based on the gold } \\
\text { standard }^{1}\end{array}$} & \multirow[t]{2}{*}{$p$-value } \\
\hline & & No & Yes & \\
\hline Sex & & & & $<0.001$ \\
\hline Male & $4765(47.4)$ & 4154 (87.2) & $611(12.8)$ & \\
\hline Female & $5275(52.6)$ & 4311 (81.7) & 964 (18.3) & \\
\hline Age group (y) & & & & $<0.001$ \\
\hline $35-45$ & 4416 (44.0) & 4185 (94.8) & $231(5.2)$ & \\
\hline $46-55$ & 3339 (33.3) & 2798 (83.8) & $541(16.2)$ & \\
\hline $56-65$ & 2285 (22.8) & 1482 (64.9) & $803(35.1)$ & \\
\hline Marital status & & & & 0.800 \\
\hline Married & 9054 (80.2) & 7632 (84.3) & $1422(15.7)$ & \\
\hline Single & $986(9.8)$ & $833(84.5)$ & $153(15.5)$ & \\
\hline Length of education (y) & & & & $<0.001$ \\
\hline Illiterate & 2484 (24.8) & 1793 (72.2) & 691 (27.8) & \\
\hline$\leq 5$ & 3838 (38.2) & 3280 (85.5) & $558(14.5)$ & \\
\hline $6-9$ & $1668(16.6)$ & 1505 (90.2) & $163(9.7)$ & \\
\hline $10-12$ & $1268(12.6)$ & 1174 (92.6) & $94(7.4)$ & \\
\hline$\geq 13$ & 782 (7.8) & 713 (91.2) & $69(8.8)$ & \\
\hline Residential area & & & & $<0.001$ \\
\hline Urban & 5953 (59.2) & 5070 (85.2) & $883(14.8)$ & \\
\hline Rural & 4087 (40.8) & 3395 (83.1) & $692(16.9)$ & \\
\hline \multicolumn{2}{|c|}{ Socioeconomic status (quintile) } & & & $<0.001$ \\
\hline 1st (the poorest) & $1996(20.0)$ & 1623 (81.3) & $373(18.7)$ & \\
\hline 2nd & $1995(20.0)$ & $1655(83.0)$ & $340(17.0)$ & \\
\hline $3 r d$ & $1997(20.0)$ & 1673 (83.8) & $324(16.2)$ & \\
\hline 4th & $2000(20.0)$ & 1706 (85.2) & $294(14.8)$ & \\
\hline 5th (the richest) & $1992(20.0)$ & $11757(88.2)$ & $235(11.8)$ & \\
\hline
\end{tabular}

Values are presented as number (\%).

RaNCD, Ravansar Non-Communicable Diseases; HTN, hypertension.

${ }^{1}$ Based on blood pressure measurements and/or taking anti-hypertensive medication.

years, and the mean age of the female participants was $48.3 \pm$ 8.4 years. In total, 2484 of the participants were illiterate (24.8\%), and only $7.8 \%$ had a post-secondary education. Almost $41.0 \%$ of the participants lived in rural areas (Table 1).

In the self-reported assessments, 25 people did not answer the questions and 61 were unaware of the concept of high BP; these participants were excluded from the study. Over $16 \%$ of the study population $(n=1681 ; 16.8 \%)$ self-identified as having HTN, of whom $24.5 \%(n=412)$ had no HTN based on BP measurements or treatment for HTN (Figure 1). Based on history of treatment and/or BP measurements, 1571 participants had HTN (15.7\%), of whom 297 (18.9\%) were not aware of their disease, and 313 (19.9\%) had uncontrolled HTN despite 


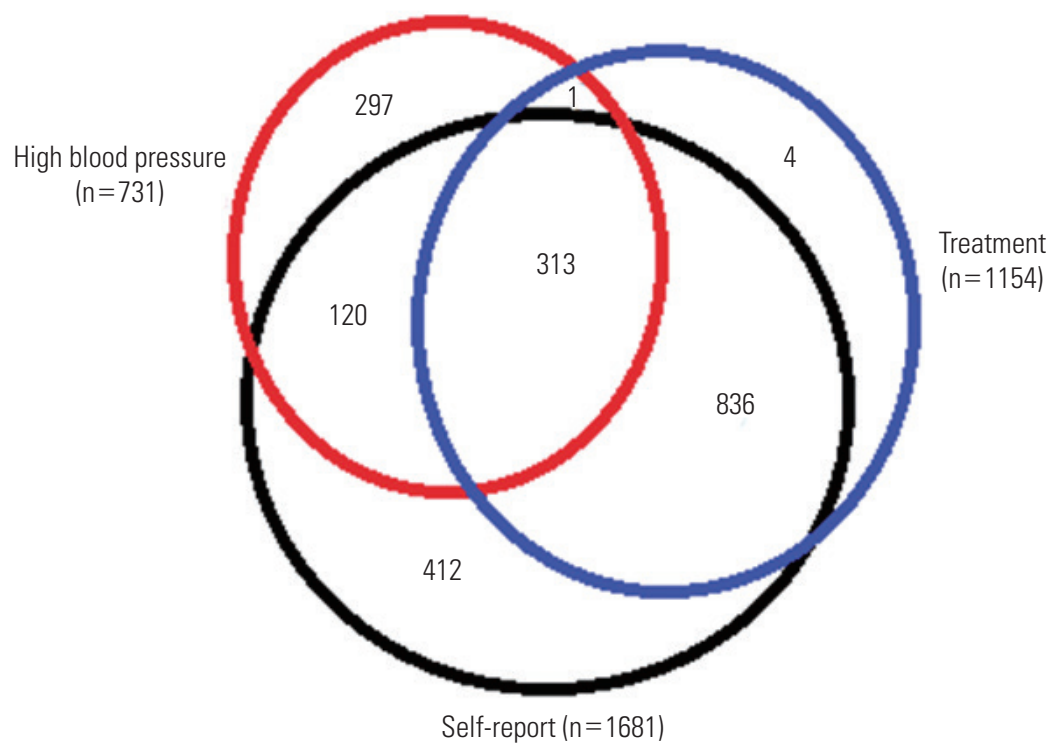

Figure 1. Frequency of people with self-reported, objectively measured hypertension and those who have received medication.

Table 2. Validity of self-reported hypertension in participants of RaNCD cohort

\begin{tabular}{|c|c|c|c|c|c|c|c|c|c|c|}
\hline \multirow{2}{*}{ Self-reported HTN } & \multicolumn{2}{|c|}{ Gold standard (n) } & \multirow{2}{*}{ Accuracy } & \multirow{2}{*}{ Kappa } & \multirow{2}{*}{ Sensitivity } & \multirow{2}{*}{ Specificity } & \multirow{2}{*}{ LR+ } & \multirow{2}{*}{ LR- } & \multirow{2}{*}{ PPV } & \multirow{2}{*}{ NPV } \\
\hline & No & Yes & & & & & & & & \\
\hline No & 7999 & 302 & 92.8 & 73.4 & 75.5 & 96.4 & 20.8 & 0.2 & 80.8 & 95.1 \\
\hline Yes & 412 & 1269 & $(92.3,93.3)$ & $(71.9,75.5)$ & $(73.3,77.5)$ & $(95.9,96.8)$ & $(18.6,23.3)$ & $(0.2,0.3)$ & $(78.8,82.0)$ & $(94.6,95.6)$ \\
\hline
\end{tabular}

Values are presented as \% (95\% confidence interval).

RaNCD, Ravansar Non-Communicable Diseases; HTN, hypertension; LR+, positive likelihood ratio; LR-, negative likelihood ratio; PPV, positive predictive value; NPV, negative predictive value.

receiving treatment (Figure 1). Furthermore, 682 patients (59.1\%) used 1 medication, 316 patients (27.4\%) used 2 medications, and 152 (13.2\%) used 3 medications. The highest number of reported anti-hypertensive treatments was 6 drugs used simultaneously. The sensitivity, specificity, and kappa values for self-reported HTN were $75.5 \%, 96.4 \%$, and $73.4 \%$, respectively (Table 2 ).

The multivariate assessment of factors explaining the gap (i.e., false positives and false negatives) between subjective (self-reported) and objective (BP measurements and/or treatment history) assessments of HTN suggested that the likelihood of false positives and false negatives increased with age and body mass index (BMI). There was a linear relationship between increasing BMI and the frequency of discordance of self-reported HTN, such that the odds ratio for discordance of self-reported HTN after controlling for confounding variables was 2.10 (95\% confidence interval [Cl], 1.60 to 2.76 ) times higher in those with a BMI $>35.0 \mathrm{~kg} / \mathrm{m}^{2}$ than in those with a $\mathrm{BMI}<24.9 \mathrm{~kg} / \mathrm{m}^{2}$. The odds of false positives were higher and the odds of false negatives were lower in than in males and in those with higher socioeconomic status (Table 3). Interestingly, older age and higher BMl, as well as smoking, increased the odds of both false positives and false negatives of self-reported HTN, even after adjustment for other variables. In addition, living in a rural area decreased the odds of both false positives and false negatives of self-reported HTN. While having a high wealth index decreased the likelihood of false positives for self-reported HTN, it increased the likelihood of false negatives (Table 3).

\section{DISCUSSION}

The self-reported prevalence of HTN among 35-65-year-old participants in the RaNCD cohort was $16.5 \%$, while it was $15.7 \%$ based on treatment history and/or measurements of $\mathrm{BP}$; these prevalence rates are lower than those reported in other studies for this age group $[8,15,16]$. In addition, the proportions of those who were aware of their disease and were 
Table 3. Univariate and multivariate associations of discordance between self-reported and clinically measured HTN in the RaNCD cohort ${ }^{1}$

\begin{tabular}{|c|c|c|c|c|c|c|c|}
\hline \multirow{3}{*}{ Determinants } & \multirow{3}{*}{$\begin{array}{c}\text { Discordance/ } \\
\mathbf{n}(\%)\end{array}$} & \multicolumn{6}{|c|}{ Self-reported HTN } \\
\hline & & \multicolumn{2}{|c|}{ Discordance } & \multicolumn{2}{|c|}{ False positive } & \multicolumn{2}{|c|}{ False negative } \\
\hline & & cOR $(95 \%$ CI) & aOR $(95 \% \mathrm{CI})$ & cOR $(95 \%$ CI) & aOR $(95 \% \mathrm{CI})$ & c0R $(95 \%$ CI) & aOR (95\% CI) \\
\hline Male & $320 / 4720(6.8)$ & 1.00 (reference) & - & 1.00 (reference) & 1.00 (reference) & 1.00 (reference) & 1.00 (reference) \\
\hline Female & $393 / 5259(7.5)$ & $1.11(0.95,1.30)$ & - & $1.30(1.08,1.54)$ & $1.53(1.26,1.86)$ & $0.51(0.41,0.62)$ & $0.45(0.35,0.58)$ \\
\hline $46-55$ & $274 / 3315$ (8.3) & $2.23(1.83,2.72)$ & $2.24(1.79,2.83)$ & $1.90(1.41,2.55)$ & $1.86(1.38,2.50)$ & $2.66(1.83,3.86)$ & $2.37(1.76,3.75)$ \\
\hline $56-65$ & 269/2277 (11.8) & $3.32(2.77,4.05)$ & $3.53(2.69,4.65)$ & $2.34(1.63,3.35)$ & $2.53(1.75,3.63)$ & $4.69(3.14,6.99)$ & $3.54(3.27,7.47)$ \\
\hline \multicolumn{8}{|l|}{ Marital status } \\
\hline Married & $643 / 9004(7.1)$ & 1.00 (reference) & - & 1.00 (reference) & - & 1.00 (reference) & - \\
\hline$\leq 5$ & 277/3817 (7.3) & $0.68(0.57,0.82)$ & - & $0.78(0.63,0.96)$ & - & $0.54(0.42,0.70)$ & - \\
\hline $6-9$ & $84 / 1647(5.1)$ & $0.47(0.36,0.61)$ & - & $0.66(0.48,0.91)$ & - & $0.40(0.26,0.61)$ & - \\
\hline $10-12$ & $55 / 1262(4.4)$ & $0.40(0.29,0.54)$ & - & $0.77(0.56,1.05)$ & - & $0.41(0.27,0.63)$ & - \\
\hline$\geq 13$ & 45/781 (5.8) & $0.53(0.38,0.47)$ & - & $0.63(0.43,0.92)$ & - & $0.53(0.34,0.81)$ & - \\
\hline \multicolumn{8}{|c|}{ Body mass index $\left(\mathrm{kg} / \mathrm{m}^{2}\right)$} \\
\hline$<24.9$ & $141 / 2895(4.9)$ & 1.00 (reference) & 1.00 (reference) & 1.00 (reference) & 1.00 (reference) & 1.00 (reference) & 1.00 (reference) \\
\hline $25.0-29.9$ & 288/4304 (6.7) & $1.40(1.13,1.72)$ & $1.18(0.98,1.40)$ & $1.05(0.84,1.30)$ & $1.04(0.83,1.31)$ & $1.46(1.11,1.90)$ & $1.30(0.99,1.72)$ \\
\hline $30.0-34.9$ & 203/2116 (9.7) & $2.07(1.65,2.58)$ & $1.62(1.33,1.97)$ & $1.46(1.14,1.86)$ & $1.53(1.18,1.97)$ & $2.00(1.50,2.68)$ & $1.59(1.17,2.15)$ \\
\hline$\geq 35.0$ & 73/581 (12.6) & $2.80(2.08,3.78)$ & $2.10(1.60,2.76)$ & $1.69(1.19,2.42)$ & $1.78(1.22,2.60)$ & $2.67(1.82,3.92)$ & $1.97(1.31,2.95)$ \\
\hline \multicolumn{8}{|l|}{ Cigarette smoking } \\
\hline No & $284 / 4511(6.3)$ & 1.00 (reference) & - & 1.00 (reference) & 1.00 (reference) & 1.00 (reference) & - \\
\hline Yes & $425 / 5451(7.8)$ & $1.21(1.06,1.39)$ & - & $1.21(1.06,1.39)$ & $1.76(1.43,2.16)$ & $0.94(0.78,1.13)$ & - \\
\hline \multicolumn{8}{|c|}{ Socioeconomic status (quintile) } \\
\hline 1st (the poorest) & 140/1985 (7.1) & 1.00 (reference) & - & 1.00 (reference) & 1.00 (reference) & 1.00 (reference) & 1.00 (reference) \\
\hline 2nd & $152 / 1984(7.7)$ & $1.09(0.86,1.38)$ & - & $0.84(0.66,1.08)$ & $0.83(0.65,1.07)$ & $1.21(0.92,1.60)$ & $1.14(0.89,1.52)$ \\
\hline $3 r d$ & 136/1982 (6.9) & $0.97(0.76,1.23)$ & - & $0.89(0.61,1.01)$ & $0.86(0.74,0.95)$ & $1.17(1.03,1.61)$ & $1.04(0.82,1.61)$ \\
\hline 4th & 145/1991 (7.3) & $1.04(0.81,1.32)$ & - & $0.82(0.56,1.00)$ & $0.82(0.71,0.90)$ & $1.31(1.07,1.35)$ & $1.21(1.00,1.21)$ \\
\hline 5th (the richest) & $135 / 1980(6.8)$ & $0.96(0.75,1.23)$ & - & $0.86(0.71,1.06)$ & $0.77(0.62,0.96)$ & $1.10(0.87,1.41)$ & $1.29(1.01,1.67)$ \\
\hline
\end{tabular}

RaNCD, Ravansar Non-Communicable Diseases; HTN, hypertension; cOR, crude odds ratio; aOR, adjusted odds ratio; Cl, confidence interval.

${ }^{1}$ The reference category was those whose self-reported data matched the clinical data for HTN.

managing it correctly were higher than has been reported in similar previous studies [8,17-19]. This could have resulted from public awareness campaigns about the dangers of high $\mathrm{BP}$ and the importance of controlling it in recent years [19]. In
Iran in 2008, approximately $25.0 \%$ of Iranians aged $25-64$ years had HTN, of whom $34.0 \%$ were aware of having elevated BP; $25.0 \%$ were taking anti-hypertensive medications, and $24.2 \%$ of the treated patients had controlled HTN (males, 25.7\%; fe- 
males, 23.5\%) [20].

Generally, self-reported HTN has high sensitivity and specificity, and a moderate kappa and agreement coefficient [21]. In the present study, the sensitivity and specificity of self-reported HTN were $75.5 \%$ and $96.4 \%$, respectively. The sensitivity of self-reported HTN varies across countries; it was found to be $73.0 \%$ in South Korea (hereafter Korea) [22], 82.4\% in Thailand [23], $72.0 \%$ and $80.0 \%$ in white and black Americans, respectively [24], 83.2\% in Spain [25], 73.0\% in Russia, 37.7\% in China, and $31.4 \%$ in South Africa [21]. Previous studies have shown that the quality of provided health services is a reason for differences in the validity of self-reported conditions $[21,22]$. When the quality of health services improves, the sensitivity of self-reported conditions becomes higher for various diseases [22]. Since respondents' awareness of the nature of their diseases can affect the accuracy of their self-reporting, it is assumed that intervention programs - including public education campaigns, knowledge dissemination, and the infrastructure of health examination programs-may influence differences across countries in the awareness of diseases and risk factors [22].

With respect to the specificity of self-reporting, representative studies with larger samples have shown that the specificity of self-reporting is higher than its sensitivity, for nearly all chronic conditions [10,11].

Exploring the role of demographic factors in discordance showed that false positive reports were more common in females than in males, but that false negatives were more common in males than in females, which is in line with the findings of other studies [25]. The high false positive rate in females can be attributed to females more frequent use of health services compared to males [26]. Discordance increased with age for both false positives and false negatives. In similar studies, the validity of self-reporting decreased with age for most chronic diseases, such as cancer [27], stroke [28], diabetes, and HTN [29]. Given that the results of the present study and similar previous studies have shown that the specificity of self-reporting is higher than its sensitivity, and the prevalence of chronic diseases increases with aging, the age-related increase in the prevalence of chronic diseases can be considered as a reason for the reduced validity of self-reporting in older individuals.

Our findings showed no association between education and the validity of self-reported HTN. In other studies, education showed different effects on self-reporting for chronic diseases

\section{$[22,24,29]$.}

One of the unanticipated findings of the study was that the validity of self-reported HTN was higher among rural residents than among urban residents. Since rural areas have less access to quality health services than urban areas, the validity of selfreported HTN was expected to be lower in residents living in rural areas. However, the results were the opposite. This could imply that the health houses that are located across rural areas in Iran are improving local residents' awareness of HTN and diabetes as part of their mission to provide primary care services [30].

At the univariate level, smoking was associated with higher false positive and negative rates. However, at the multivariate level, no relationship was found between smoking and an increased likelihood of self-reported false positives, but an association was found between smoking and an increased likelihood of false negatives for self-reported HTN. Reports from elsewhere have shown divergent results in this regard. Significant relationships were found in studies conducted in China and Hong Kong [22,31], but no significant relationship was found in Korea [22]. Differences in the proportions of false negatives and false positives in these studies may help explain the discrepancies in their results.

Discordance became more frequent as BMI increased. The role of BMI has not been assessed in most previous studies. The relationship between overweight and the validity of selfreported HTN was only assessed in one study, which showed no relationship between the validity of self-reported HTN and BMI [32]. The relationship observed in this study might have been related to the lower use of health care and health awareness of obese participants [21,33].

The odds of successful HTN control has been reported to be $50-60 \%$ with a single medication (monotherapy) and 70-79\% with combination therapy [34]. In the present study, nearly $60 \%$ of patients used a single medication to control HTN. In similar studies, $50-80 \%$ of patients used monotherapy, and 20$30 \%$ used combination therapy [8,35-37]. Since using antihypertensive medication reduces the likelihood of stroke by 30 $40 \%$, the risk of myocardial infarction by $20-25 \%$, and the risk of heart failure by $50 \%$ on average [38], it is essential to educate patients about the proper management and control of HTN.

\section{Limitations and Strengths}

All studies conducted to determine the validity of self-reported HTN contain limitations, such as an artificially elevated 
number of false positive cases due to white coat syndrome. To avoid causing white coat syndrome, HTN was measured twice on each arm of every person, and the mean value of the 4 measurements was recorded as the BP for that individual. It is not possible to generalize the results of this study to the entire population of the PERSIAN cohort because we only examined people in the age range of 35-65 years living in a Western region of Iran. Although public health awareness about chronic conditions such as HTN might be similar throughout Iran, studies regarding this issue need to be replicated at all the sites of the PERSIAN cohort. Despite these limitations, the present study included a large sample size and used highquality cohort data collected by trained researchers.

To further increase the validity of self-reporting, health programs should be implemented with the goal of improving the general knowledge of the public, especially older people. In the absence of a countrywide HTN control and detection program, self-reporting can be used as an appropriate tool for control and prevention of diseases. Generally, the validity of self-reporting is lower in older and obese $\left(B M I>30.0 \mathrm{~kg} / \mathrm{m}^{2}\right)$ people than in young people and those with a normal BMI. Given that those groups are at a higher risk of developing chronic diseases such as HTN and diabetes, health intervention programs and improvements in the general knowledge of the public are essential.

\section{CONFLICT OF INTEREST}

The author hase no conflicts of interest associated with the material presented in this paper.

\section{ACKNOWLEDGEMENTS}

RaNCD is part of the PERSIAN national cohort, and we would like to thank Prof. Reza Malekzadeh, the Deputy of Research and Technology at the Ministry of Health and Medical Education of Iran and Director of the PERSIAN cohort, as well as Dr. Hossein Poustchi, the Executive Director of the PERSIAN cohort, for all their support during the design and implementation of the RaNCD cohort.

This study was supported by the Ministry of Health and Medical Education of Iran and Kermanshah University of Medical Sciences (grant No. 92472).

\section{ORCID}

Farid Najafi http://orcid.org/0000-0001-8530-7180

Yahya Pasdar http://orcid.org/0000-0001-8682-5721

Ebrahim Shakiba http://orcid.org/0000-0002-9603-4293

Behrooz Hamzeh http://orcid.org/0000-0002-1110-0870

Mitra Darbandi http://orcid.org/0000-0002-9173-8814

Mahdi Moradinazar http://orcid.org/0000-0001-7033-6755

Jafar Navabi http://orcid.org/0000-0001-5341-2904

Bita Anvari http://orcid.org/0000-0003-0644-4641

Mohammad Reza Saidi http://orcid.org/0000-0003-45705314

Shahrzad Bazargan-Hejazi http://orcid.org/0000-00018361-5198

\section{REFERENCES}

1. NCD Risk Factor Collaboration (NCD-RisC). Worldwide trends in blood pressure from 1975 to 2015: a pooled analysis of 1479 population-based measurement studies with $19 \cdot 1$ million participants. Lancet 2017;389(10064):37-55.

2. Zhong Y, Rosengren A, Fu M, Welin L, Welin C, Caidahl K, et al. Secular changes in cardiovascular risk factors in Swedish 50year-old men over a 50-year period: the study of men born in 1913, 1923, 1933, 1943, 1953 and 1963. Eur J Prev Cardiol 2017; 24(6):612-620.

3. Lawes CM, Vander Hoorn S, Law MR, Elliott P, MacMahon S, Rodgers A. Blood pressure and the global burden of disease 2000. Part II: estimates of attributable burden. J Hypertens 2006;24(3):423-430.

4. Chobanian AV, Bakris GL, Black HR, Cushman WC, Green LA, Izzo JL Jr, et al. The seventh report of the joint national committee on prevention, detection, evaluation, and treatment of high blood pressure: the JNC 7 report. JAMA 2003;289(19): 2560-2572.

5. Kearney PM, Whelton M, Reynolds K, Muntner P, Whelton PK, He J. Global burden of hypertension: analysis of worldwide data. Lancet 2005;365(9455):217-223.

6. Centers for Disease Control and Prevention (CDC). Vital signs: prevalence, treatment, and control of hypertension--United States, 1999-2002 and 2005-2008. MMWR Morb Mortal Wkly Rep 2011;60(4):103-108.

7. Centers for Disease Control and Prevention (CDC). Vital signs: prevalence, treatment, and control of high levels of low-density lipoprotein cholesterol—United States, 1999-2002 and 
2005-200. MMWR Morb Mortal Wkly Rep 2011;60(4):109-114.

8. Wolf-Maier K, Cooper RS, Kramer H, Banegas JR, Giampaoli S, Joffres MR, et al. Hypertension treatment and control in five European countries, Canada, and the United States. Hypertension 2004;43(1):10-17.

9. Fagard RH, Van Den Enden M, Leeman M, Warling X. Survey on treatment of hypertension and implementation of World Health Organization/International Society of Hypertension risk stratification in primary care in Belgium. J Hypertens 2002; 20(7):1297-1302.

10. Poustchi H, Eghtesad S, Kamangar F, Etemadi A, Keshtkar AA, Hekmatdoost $A$, et al. Prospective epidemiological research studies in Iran (the PERSIAN Cohort Study): rationale, objectives, and design. Am J Epidemiol 2018;187(4):647-655.

11. Eghtesad S, Mohammadi Z, Shayanrad A, Faramarzi E, Joukar F, Hamzeh $B$, et al. The PERSIAN cohort: providing the evidence needed for healthcare reform. Arch Iran Med 2017;20(11):691695.

12. Pasdar Y, Najafi F, Moradinazar M, Shakiba E, Karim H, Hamzeh $B$, et al. Cohort profile: Ravansar Non-Communicable Disease cohort study: the first cohort study in a Kurdish population. Int J Epidemiol 2019. doi: https://doi.org/10.1093/ije/dyy296.

13. Whelton PK, Carey RM, Aronow WS, Casey DE Jr, Collins KJ, Dennison Himmelfarb C, et al. 2017 ACC/AHA/AAPA/ABC/ ACPM/AGS/APhA/ASH/ASPC/NMA/PCNA guideline for the prevention, detection, evaluation, and management of high blood pressure in adults: a report of the American College of Cardiology/American Heart Association Task Force on Clinical Practice Guidelines. J Am Coll Cardiol 2018;71(19):e127-e248.

14. Rutstein SO, Johnson K. DHS comparative reports No. 6: the DHS wealth index; 2004 [cited 2019 Mar 19]. Available from: https://www.dhsprogram.com/pubs/pdf/CR6/CR6.pdf.

15. Ong KL, Cheung BM, Man YB, Lau CP, Lam KS. Prevalence, awareness, treatment, and control of hypertension among United States adults 1999-2004. Hypertension 2007;49(1):69-75.

16. Sharma AM, Wittchen HU, Kirch W, Pittrow D, Ritz E, Göke B, et al. High prevalence and poor control of hypertension in primary care: cross-sectional study. J Hypertens 2004;22(3):479486.

17. Anchala R, Kannuri NK, Pant H, Khan H, Franco OH, Di Angelantonio $E$, et al. Hypertension in India: a systematic review and meta-analysis of prevalence, awareness, and control of hypertension. J Hypertens 2014;32(6):1170-1177.

18. Cooper RS, Wolf-Maier K, Luke A, Adeyemo A, Banegas JR, Forrester $\mathrm{T}$, et al. An international comparative study of blood pressure in populations of European vs. African descent. BMC Med 2005;3:2.

19. Lu J, Lu Y, Wang X, Li X, Linderman GC, Wu C, et al. Prevalence, awareness, treatment, and control of hypertension in China: data from 1.7 million adults in a population-based screening study (China PEACE Million Persons Project). Lancet 2017; 390(10112):2549-2558.

20. Esteghamati A, Abbasi M, Alikhani S, Gouya MM, Delavari A, Shishehbor $\mathrm{MH}$, et al. Prevalence, awareness, treatment, and risk factors associated with hypertension in the Iranian population: the national survey of risk factors for noncommunicable diseases of Iran. Am J Hypertens 2008;21(6):620-626.

21. Tenkorang EY, Sedziafa P, Sano Y, Kuuire V, Banchani E. Validity of self-report data in hypertension research: findings from the Study on Global Ageing and Adult Health. J Clin Hypertens (Greenwich) 2015;17(12):977-984.

22. Chun H, Kim IH, Min KD. Accuracy of self-reported hypertension, diabetes, and hypercholesterolemia: analysis of a representative sample of Korean older adults. Osong Public Health Res Perspect 2016;7(2):108-115.

23. Thawornchaisit P, De Looze F, Reid CM, Seubsman SA, Sleigh A; Thai Cohort Study Team. Validity of self-reported hypertension: findings from the Thai Cohort Study compared to physician telephone interview. Glob J Health Sci 2013;6(2):1-11.

24. Teteh DK, Lee JW, Montgomery SB, Wilson CM. Validity of selfreported high blood pressure among black and white seventh-day Adventists. Int J Health Sci Res 2017;7(7):212-220.

25. Alonso A, Beunza JJ, Delgado-Rodríguez M, Martínez-González MA. Validation of self reported diagnosis of hypertension in a cohort of university graduates in Spain. BMC Public Health 2005;5:94.

26. Bigdeli MA, Hashemi Nazari SS, Khodakarim S, Brodati H, Mafi $\mathrm{H}$, Gafari Z, et al. Factors associated with self-care behavior in patients with type ii diabetes. J Mazandaran Univ Med Sci 2015; 25(125):61-72 (Persian).

27. Bergmann MM, Calle EE, Mervis CA, Miracle-McMahill HL, Thun MJ, Heath CW. Validity of self-reported cancers in a prospective cohort study in comparison with data from state cancer registries. Am J Epidemiol 1998;147(6):556-562.

28. Engstad T, Bonaa KH, Viitanen M. Validity of self-reported stroke: the Tromso Study. Stroke 2000;31(7):1602-1607.

29. Goldman N, Lin IF, Weinstein M, Lin YH. Evaluating the quality of self-reports of hypertension and diabetes. J Clin Epidemiol 2003;56(2):148-154.

30. Farzadfar F, Murray CJ, Gakidou E, Bossert T, Namdaritabar H, 
Alikhani S, et al. Effectiveness of diabetes and hypertension management by rural primary health-care workers (Behvarz workers) in Iran: a nationally representative observational study. Lancet 2012;379(9810):47-54.

31. Ahn S, Smith ML, Cho J, Bailey JE, Ory MG. Hypertension awareness and associated factors among older Chinese adults. Front Public Health 2013;1:67.

32. Giles WH, Croft JB, Keenan NL, Lane MJ, Wheeler FC. The validity of self-reported hypertension and correlates of hypertension awareness among blacks and whites within the stroke belt. Am J Prev Med 1995;11(3):163-169.

33. Friedman-Gerlicz C, Lilly I. Misclassification rates in hypertension diagnosis due to measurement errors. Soc Ind Appl Math 2009;2(2):46-57.

34. Elliott WJ. Drug interactions and drugs that affect blood pressure. J Clin Hypertens (Greenwich) 2006;8(10):731-737.

35. Egan BM, Bandyopadhyay D, Shaftman SR, Wagner CS, Zhao Y,
Yu-Isenberg KS. Initial monotherapy and combination therapy and hypertension control the first year. Hypertension 2012; 59(6):1124-1131.

36. Li W, Gu H, Teo KK, Bo J, Wang Y, Yang J, et al. Hypertension prevalence, awareness, treatment, and control in 115 rural and urban communities involving 47000 people from China. J Hypertens 2016;34(1):39-46.

37. Valizadeh G, Bizhani M, Bahramali E, Kouhpayeh SA. Investigating the consistancy rate of hypertension treatment through guide line JNC-7, in patients who were referred to health centers and health houses of Fasa University of Medical Sciences 2012. J Fasa Univ Med Sci 2014;4(1):74-80 (Persian).

38. Woollard J, Burke V, Beilin LJ. Effects of general practice-based nurse-counselling on ambulatory blood pressure and antihypertensive drug prescription in patients at increased risk of cardiovascular disease. J Hum Hypertens 2003;17(10):689. 